\title{
The manifestation of creativity of younger school students
}

\author{
Tazhigalieva K.T. ${ }^{1}$, A.A. Bekimbetova ${ }^{2}$ \\ ${ }^{1}$ Primary school teacher of secondary school №38, Uzbekistan, Nukus \\ ${ }^{2}$ Candidate of Pedagogical Science Associate Professor, head of department, "Preschool education and \\ defectology" Nukus State Pedagogical Institute Uzbekistan, Nukus \\ Email: tazhigalieva_k@umail.uz
}

\begin{abstract}
The article presents a question about the technology of critical thinking in primary school children. Forms of work on the formation of this technology are proposed. To achieve a new quality education that corresponds to important aspects of modern society - this is the main goal of reforming and improving the educational system.

Keywords: Junior school student, critical thinking technology, creativity, ability, creative thinking. Primary school age is a very important period of school.

\section{INTRODUCTION}

The level of intelligence and personality, the desire and ability to learn self-confidence depends on the full-fledged life of the child. It is in interaction with adults that the child develops as a person,develops creative thinking of the child. The transition to school is a fundamental fact that forms the personality of the younger student and his cognitive processes. The lesson as a process of personal development with priorities of individuality, self - realization and openness is one of the leading positions. To implement them , we have a need to use new techniques and modern educational technologies in our teaching activities.

The purpose of this technology is to develop students ' thinking skills, which are necessary not only in school, but also in everyday life. What does a modern primary school mean for a child? First of all, it is in his life and the basis for further training. What should a student learn when leaving the walls of an elementary school? First of all - the ability to learn. Universal training actions should be formed in it. To do this, it is necessary to develop technologies for developing critical thinking in the classroom.

The technology of developing critical thinking allows you to build the educational process in such a way that the student's personality and the information received interact on a scientific basis, and it is aimed at developing and improving the skills of information perception, analysis, processing and application of information from the outside. Critical thinking is the mental activity of a person, which is accompanied by improving the skills of perception of information, its analysis, processing and application from the outside.

Critical thinking is a mental activity of a person, which is accompanied by high objectivity and perception of the surrounding world, objects, details and details. Critical thinking and working within the framework of this technology allows you to awaken and develop ,improve and work out such qualities of students as:

- carefully perceive the ideas of other students and adults, i.e. flexibility;

- plan clearly, that is, think logically and Express your thoughts clearly;

- correctly use your own and other people's mistakes for further experience, ability and ability to correct them;

- persistently achieve the goal, i.e. goal setting;

- the ability and desire to engage in self - study on their own;
\end{abstract}

for the fruitful introduction of critical thinking technology in the team of children, it is necessary to:

- organize group work in the classroom;

- encourage active participation of younger students in the educational process;;

- to develop communication;

treat each student as something valuable,even if their academic performance is low;

- to increase the interest in self-education;

- use graphic material and techniques for visualizing objects and phenomena, etc.

For primary school students, it is useful to master schematic

images, models, and the process of creating them.At the same time,the main components of thinking are developed:synthesis,analysis, generalization, as well as abstraction and drawing up three-dimensional figures.

The lesson in the use of critical thinking technology has three basic phases: challenge, comprehension, reflection. Organization of the lesson it is this structure of activity in the lesson that directly corresponds to the stage of human perception:

- attitude and analysis of past experience;

- introduction to new material and its "processing»;

- reflection and application in practice.

The "challenge" stage. Challenge students to what they already know about a given topic, the student 
remembers what they know ,and asks questions that they would like to answer .

\section{TASKS OF THIS STAGE:}

- updating existing knowledge and ideas;

- determining the direction of studying the topic by the students themselves.

In the process of implementing the challenge phase, students freely Express their point of view about the topic being studied, are not afraid to make a mistake and be corrected by the teacher or classmates.

Here, the combination of group and individual work has high results. Group work will allow you to hear other opinions, Express your point of view without the risk of making a mistake. The exchange of opinions also contributes to the creation of new ideas, many of which are effective and even unexpected. At this stage, the teacher should receive students ' memories, exchange opinions calmly, without conflicts, and record and systematize the data obtained.

Exercises of the "Challenge" stage:

- "Brainstorming»;

- Piggy Bank of ideas;

- cluster

- "Would you believe that...",

- "I know - I Want to know - I found out", etc.

The table of "thick" and "thin" questions at the "Challenge" stage are questions before studying the topic that students want to get answers to while studying the topic. Subtle questions have a clear answer. Thick questions are problematic questions with different answers.

Subtle questions? Thick questions?

- who - give an explanation why...

- what.- why do you think...

- when... - why do you think...

- maybe.- what's the difference...

- will... - suggest what will happen if...

- what was the name of... - what if.

The admission game "will Test whether you ? "(the teacher asks questions, the students answer - "Yes or no").

1. 1.Do you believe that elephants live in the desert? - Yes - no

2.do You believe that there are no plants in the desert? - Yes - no

3.do you believe that the desert is hot?- Yes - no

4.do you believe it Snows in the desert? - no, etc.

The "comprehension" stage.Within its framework, the student's direct work with information takes place, the work is clearly directed and necessarily meaningful. The student has information, the work is clearly directed and necessarily meaningful.The student has the opportunity to think and understand the origin of the object being studied, in the process of filtering old and new information, formulates questions about the subject, determines their own position and attitude.

Direct contact with new material(text, film, presentation, theme material)prepares students for analysis and discussion, the work is carried out individually or in pairs.

The final stage is "Reflection".This is where new ideas and information are expressed in the individual student's own words. Each student has fully comprehended the material and is ready to summarize the information received in the process of exchanging opinions between students not only with each other, but also with the teacher. At this stage, you can conduct a "Cinquain", "Letter to the teacher", "Five-minute essay", etc.

The "five-minute essay" helps students summarize their knowledge of the topic they are studying. the teacher asks students to complete the following tasks:

1) write what you learned about this topic;

2) ask a question that they didn't get an answer to.

The teacher collects papers and uses them for future lessons.

Techniques used at the "Reflection" stage:

- complete filling in clusters, tables, fixing cause-and-effect relationships between sections of the material; - return to the basic concepts of words, correct and incorrect statements;

the answers to these questions;

For the full development of a child's creative personality, it is necessary to

Expand the range of intellectual activities available to children,the most diverse and unusual.

Thus, the creative manifestations of a child are those manifestations in which they managed to realize their individuality.

It is necessary that any lesson was aimed at developing the creative abilities of students. 


\section{REFERENCES:}

1. M. G. Voinova. "Pedagogical technologies and pedagogical skills". "IQTISOD - MOLIYA", Tashkent - 2006,90-91B.

2. L. V. Golish,D. M. fayzullayeva. "Pedagogy of texnologiyalari logicalities VA realisticish". Tashkent - 2010.46 b.

3. Methodological guide for teachers. « Ozbekiston milliy ensiklopediya 